\title{
Correlation between Programmed Death Ligand-1 (PD-L1) Expression and Driver Gene Mutations in Non-Small Cell Lung Carcinoma- Adenocarcinoma Phenotype
}

\author{
Rahul Kumar Pandey ${ }^{1,2}$, Saumya Shukla ${ }^{1 *}$, Nuzhat Husain ${ }^{1}$, Mohammad Hayatul \\ Islam $^{2}$, Rahat Hadi ${ }^{3}$, Surya Kant Tripathi ${ }^{4}$, Ashish Singhal ${ }^{5}$
}

\begin{abstract}
Background: Targeted therapy in adenocarcinoma is recommended. The use of immune check point inhibitors for the treatment of Non-small cell lung carcinoma (NSCLC) is used as both first-line and the second-line treatment strategy. The current study was undertaken to assess the frequency of programmed cell death ligand-1 (PD-L1) expression with anaplastic lymphoma kinase (ALK), proto-oncogene 1, receptor tyrosine kinase (ROS), epidermal growth factor receptor (EGFR), Kirsten rat sarcoma (KRAS), and v-Raf murine sarcoma viral oncogene homolog B (BRAF)V600E driver gene mutations in NSCLC adenocarcinoma phenotype. It assesses the frequencies of all markers in the cases where both treatment strategies can be implemented. Expression of the all markers was further compared with demographic, clinical parameters, and overall survival rate. Materials and Methods: The formalin-fixed paraffinembedded (FFPE) tissue blocks were used in immunohistochemistry (IHC) staining and real-time polymerase chain reaction (RT-PCR) for determining the driver genes and PD-L1 expression in the 100 NSCLC-Adenocarcinoma cases. Results: PD-L1 positivity was observed in $26.36 \%(n=29 / 110)$ cases in adenocarcinoma. No significant differences in PD-L1 expression were observed among patients harboring ALK, ROS1, EGFR, KRAS, and BRAF mutations EGFR mutations had significant association with smoking status. ( $p=0.008$ ), Thyroid transcription factor 1 (TTF1) $(\mathrm{p}=0.0005)$ and Napsin $(\mathrm{p}=0.002)$ expression. ALK gene re-arrangement was significantly related to age $(\mathrm{p}=0.001)$, gender $(p=0.009)$ and smoking status $(p=0.043)$. The single versus multiple driver mutations were significantly correlated with smoking status $(\mathrm{p}=0.005)$. In the survival rate analysis, EGFR $(\mathrm{p}=0.058), \operatorname{KRAS}(\mathrm{p}=0.021)$, and PD-L1 $(\mathrm{p}=0.039)$ were significantly high with the positive versus negative group. Conclusions: The current study is a novel attempt to document the co-expression of multiple driver mutations in the NSCLC-adenocarcinoma phenotype. PD-L1 immunopositivity in NSCLC-adenocarcinoma was higher with EGFR mutation as compared to those of KRAS, ALK, ROS, and BRAF driver genes.
\end{abstract}

Keywords: Adenocarcinoma, Programmed cell death ligand-1 (PD-L1), Non-small cell lung carcinoma (NSCLC)

Asian Pac J Cancer Prev, 23 (1), 131-142

\section{Introduction}

The International Association for the Study of Lung Cancer (IASLC) has recommended mandatory testing for anaplastic lymphoma kinase (ALK), proto-oncogene 1, receptor tyrosine kinase (ROS-1), and epidermal growth factor receptor (EGFR) in all cases of NSCLC-adenocarcinoma. The Food and Drug Administration (FDA) has approved EGFR tyrosine kinase inhibitors (TKIs) for EGFR mutant tumors because they have lower toxicity as compared to conventional platinum-based chemotherapy, thus leading to significant survival rates Kirsten rat sarcoma (KRAS) gene mutations are associated with those cases consuming tobacco and are also smokers, and are the most prevalent mutation after EGFR mutations in the adenocarcinoma lung (Remon et al., 2018). Patients harboring EGFR mutations associated with KRAS mutations have an adverse prognosis due to the resistance to traditional EGFR-TKIs (Chatziandreou et al., 2015).

The novel ALK fusion-echinoderm microtubuleassociated protein-like 4 (EML4-ALK) was first discovered as a somatic gene rearrangement that leads to the production of a chimeric protein, resulting in inhibition

${ }^{1}$ Department of Pathology, Dr. Ram Manohar Lohia Institute of Medical Sciences, Lucknow, (UP), India. ${ }^{2}$ Department of Biosciences, Integral University, Lucknow, (UP), India. ${ }^{3}$ Department of Radiation Oncology, Dr. Ram Manohar Lohia Institute of Medical Sciences, Lucknow, (UP), India. ${ }^{4}$ Department of Respiratory Medicine, King George's Medical University, Lucknow, (UP), India. ${ }^{5}$ Department of Surgical Oncology, Dr. Ram Manohar Lohia Institute of Medical Sciences, Lucknow, (UP), India. *For Correspondence: saumyavarun@gmail.com 
of apoptosis and promotion of cell proliferation in tumor cells. The $A L K$ gene rearrangement is found in $3-5 \%$ of cases in NSCLC in the western population, and up to $13 \%$ in the East Asian population (Desai et al., 2013). ROS 1 fusions are potent oncogenic drivers and these rearrangements promote signal transduction programs leading to uninhibited cell survival and proliferation. ROS 1 rearrangements have been identified in $1-2 \%$ of cases in NSCLC (Mohammadi et al., 2015).

BRAF (v-Raf murine sarcoma viral oncogene homolog $\mathrm{B})$, is one of three members of the RAF kinase family: A-RAF, BRAF, C-RAF, belong to the group of serinethreonine kinases and play a vital role in mitogen-activated protein kinase (MAPK) pathways and have been identified in 1-3\% cases of NSCLC (Chen et al., 2014).

In the current scenario, chemotherapy and radiotherapy form the mainstay of treatment in the advanced- stage in NSCLC. Targeted therapy for the oncogenes is administered in cases that harbor mutations of the driver oncogenes (Lantuejoul et al., 2020). Due to the advancement and improvement in targeted therapies, the overall survival rate has improved (Kimberly et al., 2016).

The use of immune check point inhibitors for the treatment of NSCLC has led to advancement in treatment strategies. Programmed death 1 (PD-1)/Programmed cell death ligand-1 (PD-L1) inhibitors have been approved as first- or second-line therapeutic options for NSCLC (Mino-Kenudson et al., 2017; Helmy et al., 2020). PD-L1 is a member of the CD28 family, expressed mainly on B cells, T cells, NK (Natural Killer) cells, macrophages, and dendritic cells. It is the principal ligand for the PD-1 surface receptor present on activated T cells (Sterlacci et al., 2016; Sumimoto et al., 2016). Cases that harbor PD-L1 expression, respond well to the novel immunotherapeutic drugs (Topalian et al., 2012; Garon et al., 2018; Aguiar et al., 2017; Al Azhar., 2021).

A combination therapy that includes immunotherapy and chemo-radiotherapy is being investigated in NSCLC as a novel therapeutic option. The use of a multi-targeted approach may have predictive and prognostic implications in advanced NSCLC.

The current study was undertaken with the objectives to assess the frequency, co-expression of driver mutations in $A L K, R O S, E G F R, K R A S, B R A F V 600 E$ genes, and PD-L1 in NSCLC-adenocarcinoma. The co-expressed individually expressed/mutated genes were also compared with demographic features and overall survival rates.

\section{Materials and Methods}

\section{Patient Selection}

The case series involved 110 cases of NSCLC adenocarcinoma phenotypes derived from various prospective and retrospective studies from tertiary care centres. The study was approved by Institutional Ethics Committee (IEC 17/18). Biopsies from both primary $(n=98)$ and metastatic $(n=12)$ sites were included in the study. The diagnosis of the cases was done according to 2015 WHO classification of lung tumors. A basic panel of immunohistochemistry (IHC) including Napsin-A, thyroid transcription factor-1 (TTF-1) (Figure 1), and markers for squamous differentiation, namely $\mathrm{p}-40$, were used. The cases diagnosed as NSCLC-squamous cell carcinoma phenotype were excluded from the study. Detailed demographic and clinical history, including age, gender, smoking history with complete radiological details, were documented in all the cases. The tumors were staged according to pathological TNM classification as per the American Joint Committee on Cancer (AJCC) staging guidelines (eighth edition) (Amin et al., 2017). The overall survival (OS) rate was calculated for all the cases. The OS rate was defined as the time window between diagnosis and death or last follow-up.

\section{Testing for PD-L1 expression}

PD-L1 expression was analyzed using SP263 clone (Cat no.7904905) on a fully automated Ventana BenchMark XT (Ventana Medical Systems, Inc., Tucson, USA) system. A positive control (human placenta) and negative control (obtained by omitting the primary antibody) were run with each batch.

\section{Assessment of PD-L1}

PD-L1 expression was assessed in both tumor cells (TC) and immune cells (IC). Cells with membranous/ cytoplasmic PD-L1 expression were considered positive (figure 3). The percentage of cells stained and the staining intensity were assessed. The tumor proportion score (TPS) was assessed as a percentage of positive expression of PD-L1 on tumor cells, and the immune proportion score (IPS) as a percentage of PD-L1 expression on IC. The study also included a combined positive score (CPS), which combines PD-L1 expressing tumor cells and immune cells. PD-L1 expression in terms of TPS, IPS, and CPS was assessed at a cutoff of $\geq 1 \%, \geq 10 \%$, $\geq 25 \%$, and $\geq 50 \%$ (Gettinger et al., 2016).

IHC Evaluation for ALK, ROS1, BRAFV600E, and KRAS protein expression: The IHC staining for the driver genes, namely ALK, ROS1 rearrangement, and BRAFV600E and KRAS protein expression, were performed on the fully automated Ventana BenchMark XT (Ventana Medical Systems, Inc., Tucson, USA),(figure 2).

ALK staining was done by using ALK monoclonal mouse anti-human D5F3 antibody (Cat no.06683380001 Denmark USA). The Optiview ALK amplification kit was used in addition to the Optiview DAB IHC detection kit to enhance chromogen expression. Appendix tissue was used as a positive control for the $A L K$ gene rearrangement.

ROS1 testing was done using a rabbit monoclonal antibody from Cell Signaling Technology (Cat no.32875USA) at a dilution of 1:50. The positive control for ROS-1 included cases that tested positive for ROS-1 rearrangement using fluorescence in situ hybridization (FISH).

Immunohistochemistry for BRAFV600E protein expression was done using (anti-BRAF V600E (VE1) mouse monoclonal antibody (Cat no. 7904855 USA). A case of papillary carcinoma thyroid with BRAF mutation was used as a positive control for the BRAF protein expression.

KRAS protein over-expression was tested using KRAS monoclonal antibody (9.13) from Thermo Fisher Scientific 
(USA) at a dilution of 1:50. A KRAS mutant colorectal carcinoma tissue tested using real-time polymerase chain reaction (PCR) was used as a positive control for KRAS IHC (Rimkunas et al., 2012; Koperek et al., 2012; Kim et al., 2011; Biernackaet al., 2016) (Table 1).

Assessment of ALK, ROS1, KRAS, and BRAFV600E protein over-expression: Cytoplasmic and/or membranous staining was evaluated for all the driver genes. Cases that harbored strong granular cytoplasmic staining in any percentage of tumor cells for ALK protein were considered positive (Towne et al., 2012). For ROS1 re-arrangement scores were given: Score 0-No staining, Score 1- Faint staining $(+)$ in any $\%$ cells, Score 2: Moderate staining $(++)$ in $>50 \%$ cells, Score 3 : Strong granular staining $(+++)$ in $>50 \%$ cells. Cases with a score of 0 and 1 were considered negative, while cases with a score of 2 and 3 were considered positive (Watermann et al., 2015). While for KRAS and BRAF, moderate to strong granular cytoplasmic staining in $>10 \%$ tumor cells were considered as positive (Piton et al., 2015).

\section{Protocol for Immunohistochemistry}

The immuno-staining was performed on a fully automated Ventana BenchMark XT (Ventana Medical Systems, Inc., Tucson, USA), using the Optiview DAB detection kit according to the manufacturers' instructions (Jain et al., 2021).

\section{EGFR mutation analysis by real-time PCR}

DNA extraction was performed from $8-10 \mu \mathrm{m}$ thick sections of FFPE tissue block using DNA isolation kit (QIAamp ${ }^{\circledR}$ DNA FFPE Tissue Kit QIAGEN, Germany). EGFR mutations were determined with Therascreen EGFR RGQ PCR kit (QIAGEN, Germany). This EGFR kit is a real-time polymerase chain reaction (PCR) based assay that uses mutant-specific probes to identify the presence of EGFR mutations. The testing procedure involved three steps: denaturation of the template followed by annealing of primers and extension of the new DNA. The kit combines two technologies (ARMSTM, Astrazeneca, and Scorpions ${ }^{\mathrm{TM}}$, Qiagen Manchester Ltd.) to detect the mutations by real-time quantitative PCR (Clayton et al., 2000; Thelwell et al., 2000; Whitcombe et al., 1999). EGFR mutation analysis was performed using Real-Time PCR (Agilent technologies, AriaMx, USA) according to the manufacturers' instructions using delta $\mathrm{Ct}=$ (mutation $\mathrm{Ct}$-control $\mathrm{Ct}$ ) values as per the standard guidelines (US Food and Drug Administration, 2018).

\section{Statistical analysis}

Data was analyzed using Statistical Package for Social Sciences (SPSS, International Business Machines Corporation, New York, USA, version 20). The Chi-square test was used for the categorical variables or groups. Two-sided tests were used to calculate all $\mathrm{p}$ - values, and a p-value of $\leq 0.05$ was considered significant. Differences between groups in overall survival rates were examined by log-rank test and demonstrated by Kaplan -Meier curves.

\section{Results}

\section{Demographic Features and Overall survival rate}

The study group included 110 patients of NSCLC, with a mean age of 55.48 years (range 26-80 years). The majority of the cases, $34.54 \%(n=38 / 110)$, were between $51-60$ years. The male/female ratio was $1.8: 1$. The site of the biopsy was the respiratory tree in $89 \%$ $(\mathrm{n}=98 / 110)$, while the biopsy was performed from metastatic sites in $10.90 \%(\mathrm{n}=12 / 110)$ cases. At all metastatic NSCLC-adenocarcinoma, the primary (site of origin) was established in the lung using IHC, radiology.

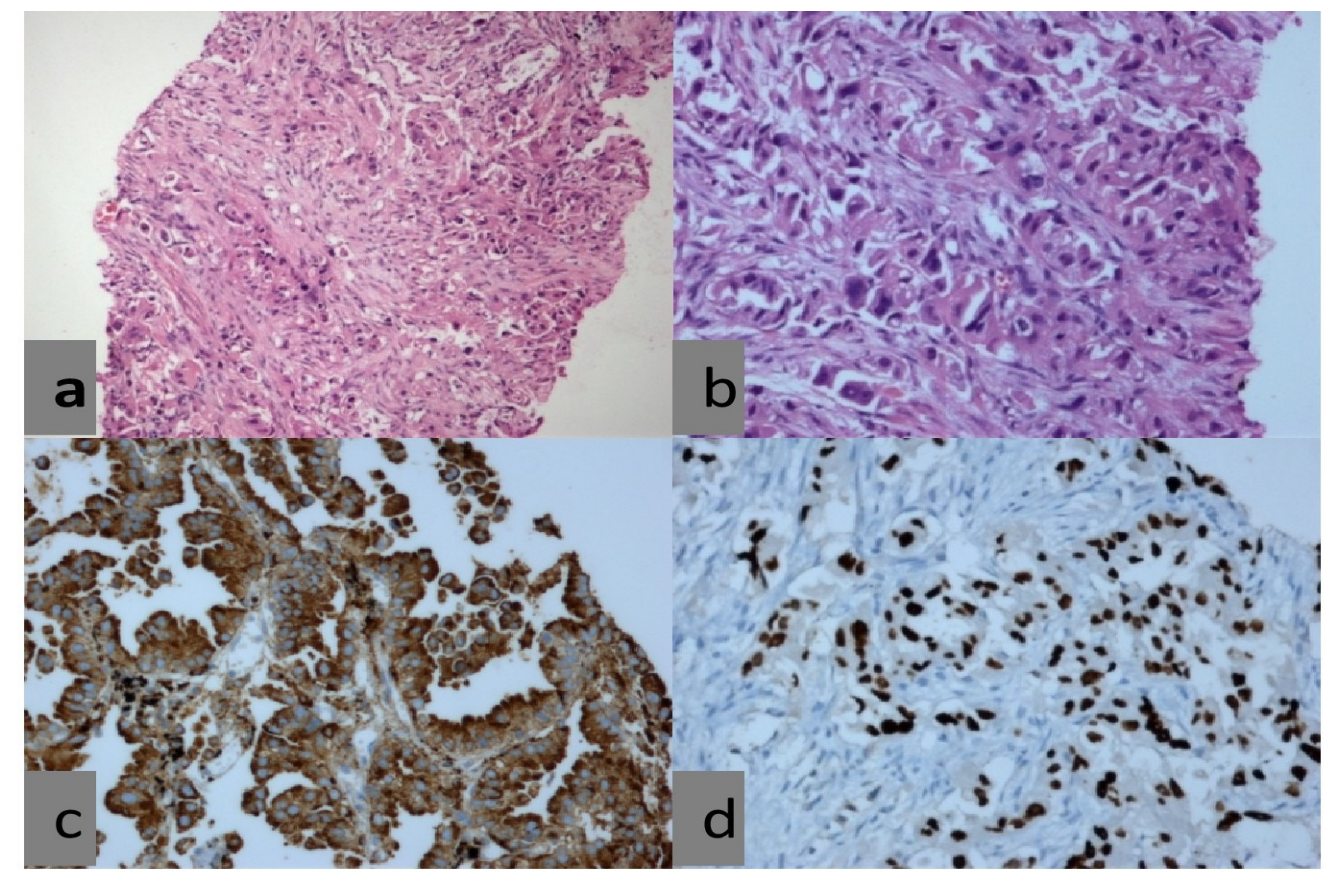

Figure 1. (a and b) Lung biopsy with tumour cells arranged in nests and acini (a H\&Ex50, b H\&Ex100) c: Napsin-A staining: Positive staining in tumour cells (DABx200) d: TTF-1 staining: Positive nuclear staining in tumour cells (DABx200) 
Table 1. Methodology for Testing and Interpretation of Molecular Markers

\begin{tabular}{|c|c|c|c|c|c|}
\hline Sr. No & Markers & Antibodies/Clone/Kit & Assessment/cut-off & Instruments/Methods & Positive Control \\
\hline 1 & ALK & D5F3 Clone & Any $\%$ of tumour cells cytoplasmic staining & $\begin{array}{c}\text { Ventana Bench Mark } \\
\text { XT / IHC }\end{array}$ & Appendix Tissue \\
\hline 2 & ROS1 & D4D6 Clone & $>50 \%$ of strong granular cytoplasmic staining & $\begin{array}{c}\text { Ventana Bench Mark } \\
\text { XT / IHC }\end{array}$ & ROS1 Positive Case \\
\hline 3 & EGFR & $\begin{array}{c}\text { QIAamp RGQ PCR } \\
\text { Kit }\end{array}$ & DELTA CT $=($ Mutation CT-Control CT $)$ & $\begin{array}{c}\text { Bio-ROD } \\
\text { CFX96/ Real-Time PCR }\end{array}$ & $\begin{array}{l}\text { Qiagen Kit Positive } \\
\text { Control }\end{array}$ \\
\hline 4 & KRAS & 9.13 Clone & $>10 \%$ Cells Cytoplasmic staining & $\begin{array}{c}\text { Ventana Bench Mark } \\
\text { XT / IHC }\end{array}$ & $\begin{array}{c}\text { Colorectal Carcinoma } \\
\text { Tissue }\end{array}$ \\
\hline 5 & BRAF & VE1 (4855) Clone & $>10$ Cells Cytoplasmic staining & $\begin{array}{c}\text { Ventana Bench Mark } \\
\text { XT / IHC }\end{array}$ & $\begin{array}{l}\text { Papillary Thyroid } \\
\text { Carcinoma Tissue }\end{array}$ \\
\hline 6 & PD-L1 & SP263 Clone & $>1 \%$ Membranous/Cytoplasmic staining & $\begin{array}{c}\text { Ventana Bench Mark } \\
\text { XT / IHC }\end{array}$ & Human Placenta Tissue \\
\hline
\end{tabular}

The metastasis sites include vertebral biopsy $(\mathrm{n}=05 / 12)$, Most of the patients harbored a combination of clinical symptoms that included cough $(\mathrm{n}=69)$, breathlessness $(\mathrm{n}=82)$, hemoptysis $(\mathrm{n}=28)$, weight loss $(\mathrm{n}=99)$, and chest pain $(\mathrm{n}=71)$. Smoking history was obtained in all cases and 39\% $(n=43 / 110)$ were categorized as current/ ex-smokers, while cases of non-smokers were $60.90 \%$ $(n=67 / 110)$.

Clinical staging was recorded in $64.54 \%(n=71 / 110)$ cases, including the tumor ( $\mathrm{T}$ stage), lymph node ( $\mathrm{N}$ stage), and metastatic ( $\mathrm{M}$ stage). Clinical stage IV was the most frequent stage present in $47.88 \%(n=34)$ cases. One-time follow-up survival data was available in $73.63 \%$ $(n=81 / 110)$ cases. The survival rate varied from 1 month to 20 months, with a mean survival rate of 7.6 months.

\section{PDL1 expression}

PD-L1 expression was assessed in all 110 cases. PD-
L1 was positive in tumor cells in $26.36 \%(n=29 / 110)$ cases. In 21 cases, PD-L1 expression was limited to only the tumor cells, while in 03 cases only the immune cells harbored PD-L1 expression. In 08 cases, PD-L1 expression was identified in both the tumor cells and immune cells.

PD-L1 expression in terms of TPS at a cut off of $\geq 1 \%$ was $26.36 \%(n=29 / 110)$ cases, cut off of $\geq 10 \%$ was $19.09 \%(n=21 / 110)$ cases, cut off of $\geq 25 \%$ was $14.54 \%(n=16 / 110)$ cases and cut off of $\geq 50 \%$ was $8.18 \%$ $(\mathrm{n}=09 / 110)$ cases (Pan et al., 2015).

PD-L1 staining in the immune cells (ICs) could be assessed in 80 out of 100 cases. PD-L1 staining was present in $13.75 \%(n=11 / 80)$ cases in immune cells, PD-L1 expression in terms of IPS at a cut off of $\geq 1 \%$ was $13.75 \%(n=11 / 80)$ cases, cut off of $\geq 10 \%$ was $7.5 \%$ ( $n=06 / 80)$ cases, cut off of $\geq 25 \%$ was $2.5 \%$ ( $n=02 / 80)$ cases and cut off of $\geq 50 \%$ was $1.25 \%(n=01 / 80)$ cases.

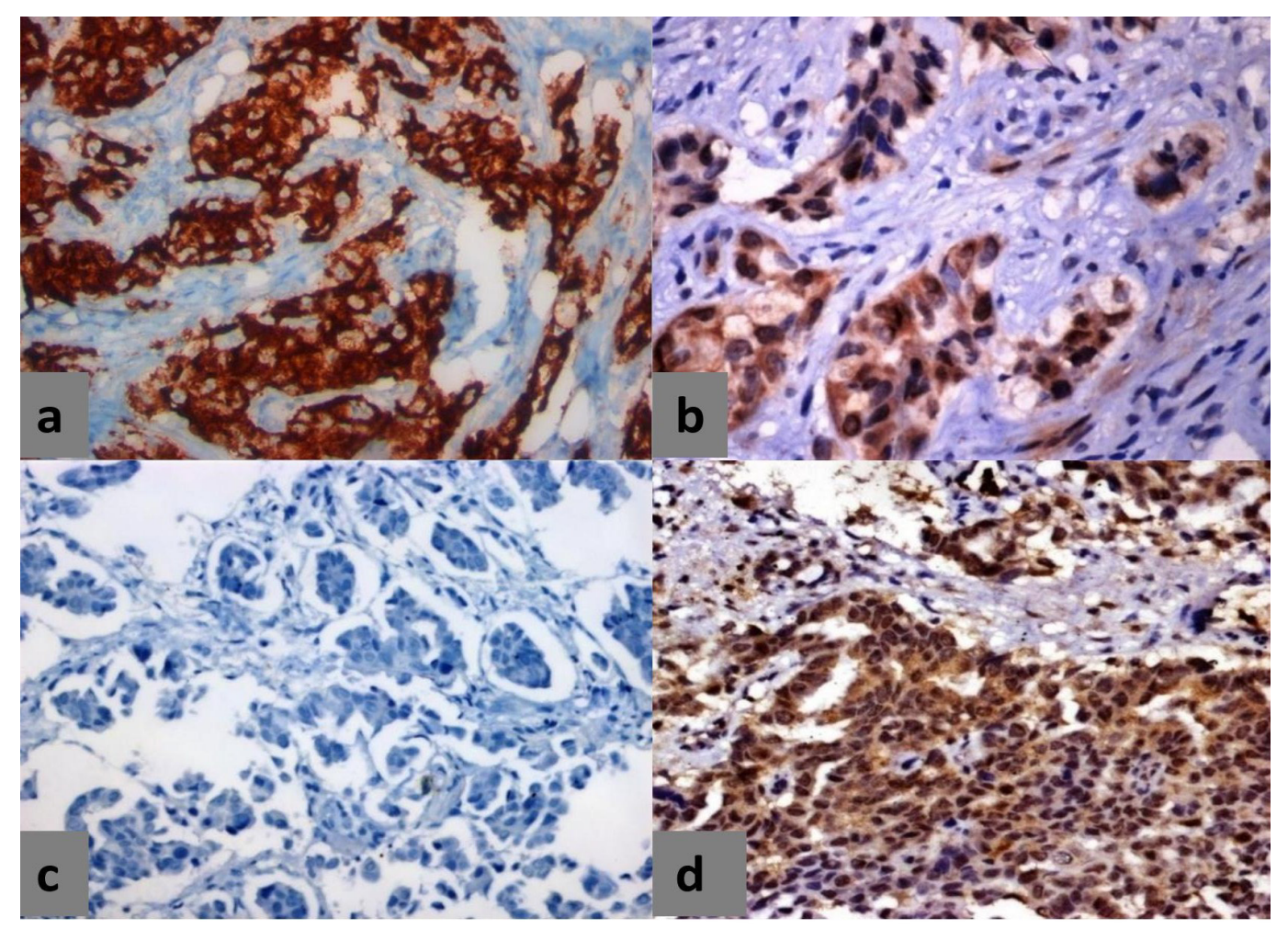

Figure 2. a) ALK protein expression using the D5F3 clone with presence of intense granular cytoplasmic staining, b) ROS-1 protein expression using the D4D6 antibody, c) Absence of staining using the BRAF V600E antibody, d) K-RAS protein over expression with intense cytoplasmic staining a $\& b=(D A B \times 200)$ c $\& d=(D A B \times 100)$ 
Table 2. Demographic and Clinico-Pathological Characteristics of the PD-L1 Expression in NSCLC-Adenocarcinoma

\begin{tabular}{|c|c|c|c|c|c|}
\hline \multicolumn{2}{|l|}{ Feature } & \multirow{2}{*}{$\begin{array}{c}\begin{array}{c}\text { Total } \\
(\mathrm{n}=110)\end{array} \\
12\end{array}$} & \multirow{2}{*}{$\begin{array}{c}\text { PDL1 + } \\
n=29(\%)\end{array}$} & \multirow{2}{*}{$\begin{array}{c}\begin{array}{c}\text { PDL1- } \\
\mathrm{n}=81(\%)\end{array} \\
08(9.87)\end{array}$} & \multirow{2}{*}{$\begin{array}{c}p \text {-value } \\
0.561\end{array}$} \\
\hline Age & $<40$ years & & & & \\
\hline & $>40$ years & 98 & $25(86.20)$ & $73(90.12)$ & \\
\hline \multirow[t]{2}{*}{ Gender } & Male & 72 & $19(65.51)$ & $53(65.43)$ & 0.993 \\
\hline & Female & 38 & $10(34.48)$ & $28(34.56)$ & \\
\hline \multirow[t]{2}{*}{ Site of Biopsy } & Respiratory tree & 98 & $25(86.20)$ & $73(90.12)$ & 0.561 \\
\hline & Metastatic site & 12 & 04 (13.79) & $08(9.87)$ & \\
\hline \multirow[t]{2}{*}{ Smoking history } & Smoker/Ex-Smoker & 43 & $14(48.27)$ & $29(35.80)$ & 0.237 \\
\hline & Non-smoker & 67 & $15(51.72)$ & $52(64.19)$ & \\
\hline \multirow[t]{2}{*}{$\begin{array}{l}\text { Histological } \\
\text { phenotype }\end{array}$} & $\begin{array}{l}\text { Adenocarcinoma with squamous differentiation } \\
\text { (Primary and metastatic) }\end{array}$ & 4 & $00(0)$ & $04(4.93)$ & 0.222 \\
\hline & $\begin{array}{l}\text { Adenocarcinoma with absence of squamous } \\
\text { differentiation (Primary and metastatic) }\end{array}$ & 106 & $29(100)$ & $77(95.06)$ & \\
\hline \multirow[t]{2}{*}{ TTF-1 } & Positive & 91 & $24(82.75)$ & $67(82.71)$ & 0.995 \\
\hline & Negative & 19 & $05(17.24)$ & $14(17.28)$ & \\
\hline \multirow[t]{2}{*}{ Napsin } & Positive & 94 & $24(82.75)$ & $70(86.41)$ & 0.631 \\
\hline & Negative & 16 & $05(17.24)$ & $11(13.58)$ & \\
\hline \multirow[t]{4}{*}{ T stage $(\mathrm{n}=71)$} & $\mathrm{T} 1$ & 4 & $01(6.25)$ & $03(5.45)$ & 0.544 \\
\hline & $\mathrm{T} 2$ & 14 & $05(31.25)$ & $09(16.36)$ & \\
\hline & $\mathrm{T} 3$ & 22 & $05(31.25)$ & $17(30.90)$ & \\
\hline & $\mathrm{T} 4$ & 31 & $05(31.25)$ & $26(47.27)$ & \\
\hline \multirow[t]{4}{*}{$\mathrm{N}$ stage $(\mathrm{n}=71)$} & N0 & 24 & $05(31.25)$ & $19(34.54)$ & 0.864 \\
\hline & N1 & 13 & $04(25)$ & $09(16.36)$ & \\
\hline & $\mathrm{N} 2$ & 26 & $05(31.25)$ & $21(38.18)$ & \\
\hline & N3 & 8 & $02(12.5)$ & $06(10.90)$ & \\
\hline \multirow[t]{2}{*}{ M stage $(n=71)$} & M0 & 37 & $08(50)$ & $29(52.72)$ & 0.847 \\
\hline & M1 & 34 & $08(50)$ & $26(47.27)$ & \\
\hline \multirow{4}{*}{$\begin{array}{l}\text { Clinical stage } \\
(\mathrm{n}=71)\end{array}$} & I & 2 & $00(0)$ & $02(3.63)$ & 0.668 \\
\hline & II & 9 & $01(6.25)$ & $08(14.54)$ & \\
\hline & III & 26 & $07(43.75)$ & $19(34.54)$ & \\
\hline & IV & 34 & $08(50)$ & $26(47.27)$ & \\
\hline \multirow[t]{4}{*}{ Survival (n=81) } & Up to 3 months & 21 & $05(29.41)$ & $16(25)$ & 0.704 \\
\hline & $>3$ months to 6 months & 17 & $05(29.41)$ & $12(18.75)$ & \\
\hline & $>6$ months to 12 months & 31 & $05(29.41)$ & $26(40.62)$ & \\
\hline & $>12$ months & 12 & $02(11.76)$ & $10(15.62)$ & \\
\hline
\end{tabular}

The intensity of staining in the tumor cells and immune cells was taken from + to +++ , of which $41.37 \%(n=12 / 29)$ cases displayed +++ intensity in tumor cells and $27.27 \%$ $(03 / 11)$ showed +++ intensity in immune cells.

\section{Combined positive score (CPS)}

The CPS at a cutoff of $\geq 1 \%$ had $36.36 \%$ cases, at $\geq 10 \%$ had $26.36 \%$ cases, at $\geq 25 \%$ had $16.36 \%$ cases and at $\geq 50 \%$ had $10 \%$ cases. There was no significant correlation with PD-L1 expression with the demographic characteristics of the cases (Table 2).

\section{EGFR, ALK, ROS, KRAS, and BRAF mutations}

The frequencies of driver gene mutations are depicted in Table 3. EGFR mutations were identified in $40.90 \%$ $(n=45 / 110)$ cases. Among EGFR mutant cases, most common alteration was exon 19 deletions and was identified in $62.22 \%(n=28 / 45)$, followed by exon 21 $(24.44 \%, n=11 / 45)$, exon $20(8.88 \%, n=04 / 45)$ and exon $18(2.22 \%, \mathrm{n}=01 / 45)$ mutations. In one case, there was a compound mutation of (exon 20) and exon 19. The age range of EGFR positive NSCLC-adenocarcinoma was 35 to 80 years, with a mean age of 56.82 years, $24.44 \%$ $(\mathrm{n}=11)$ were smokers/ex-smokers, in 38 mutant cases, a biopsy was from the primary site, while 7 biopsies were from the metastatic site.

ALK protein expression was found in $5.45 \%$ $(n=06 / 110)$ cases. All the ALK-positive cases were non-smokers, and biopsies were from the primary site contained NSCLC-adenocarcinoma phenotype.

ROS 1 protein expression was identified in $4.54 \%$ $(n=05 / 110)$ cases, In ROS 1 positive cases, 04 were 


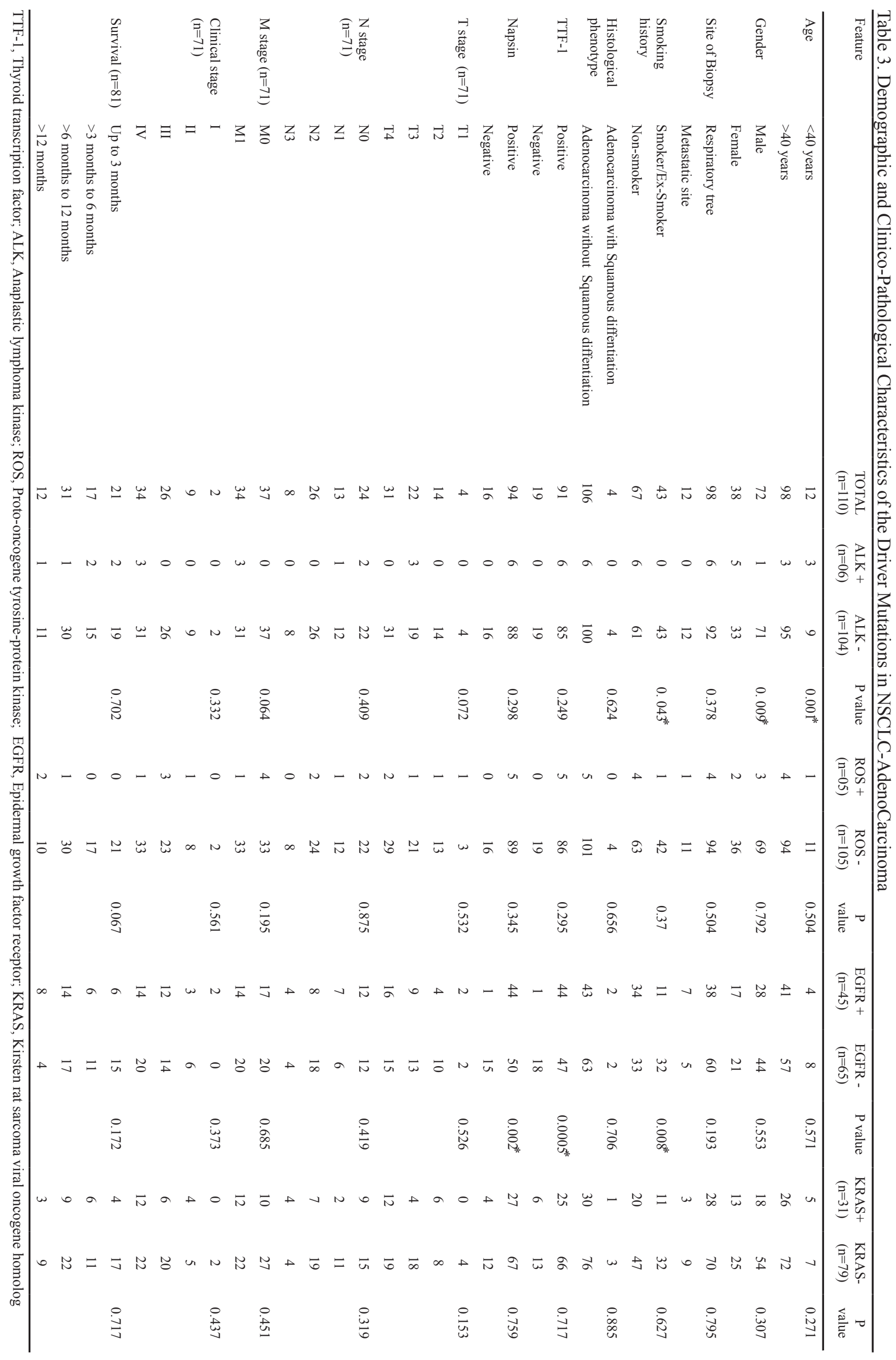


DOI:10.31557/APJCP.2022.23.1.131

Programmed Death Ligand-1(PD-L1) Expression with Driver Gene Mutations in Adenocarcinoma Lung

Table 4. PDL1 Positivity in Tumour Cells (TCs) and Immune Cells (ICs) Correlation with Multiple Driver Mutation in NSCLC-Adenocarcinoma Lung

\begin{tabular}{|c|c|c|c|c|c|c|}
\hline S. NO & MARKERS & TOTAL $(\mathrm{n}=110)$ cases $(\%)$ & PDL1 +in TCs $(\mathrm{n}=29)(\%)$ & $\mathrm{p}$ value & PDL1 + in ICs $(n=11)(\%)$ & $\mathrm{p}$ value \\
\hline \multirow[t]{2}{*}{1} & KRAS + & $31(28.18)$ & $06(20.68)$ & 0.48 & $04(36.36)$ & 0.72 \\
\hline & KRAS- & $79(71.81)$ & $23(79.31)$ & & $07(63.63)$ & \\
\hline \multirow[t]{2}{*}{2} & EGFR + & $45(40.90)$ & $11(37.93)$ & 0.83 & $03(27.27)$ & 0.52 \\
\hline & EGFR- & $65(59.09)$ & $18(62.06)$ & & $08(72.72)$ & \\
\hline \multirow[t]{2}{*}{3} & ALK + & $06(5.45)$ & $03(10.34)$ & 0.39 & $01(9.09)$ & 0.49 \\
\hline & ALK- & $104(94.54)$ & $26(68.96)$ & & $10(90.90)$ & \\
\hline \multirow[t]{2}{*}{4} & ROS + & $05(4.54)$ & $01(3.44)$ & 1 & $00(00)$ & 1 \\
\hline & ROS- & $105(95.45)$ & $28(96.55)$ & & $11(100)$ & \\
\hline
\end{tabular}

non-smokers while 01 was ex-smoker, and 04 biopsies were from the primary site while 01 biopsy was from metastasis in the cervical lymph node. One case $(01 / 5)$ was in stage II \&IV, and 03/5 were of stage III .

KRAS protein overexpression was identified in $28.18 \%(\mathrm{n}=31 / 110)$ cases, with a mean age of 53.74 years. In KRAS positive cases, $90.32 \%(\mathrm{n}=28 / 31)$ were biopsies from the primary pulmonary site, and the remaining $9.67 \%(\mathrm{n}=03 / 31)$ were from metastatic site. Squamous differentiation was identified in one case with KRAS mutations.

BRAFV600E protein expression was not identified in any of the cases; all 110 cases were negative for BRAF

Table 5. Tabular form of Single versus Multiple Driver Mutations

\begin{tabular}{|c|c|c|c|c|c|}
\hline Feature & & TOTAL & Single driver & Multiple driver & p-value \\
\hline Age & $<40$ years & 8 & $4(8.33)$ & $4(22.22)$ & 0.123 \\
\hline & $>40$ years & 58 & $44(91.66)$ & $14(77.77)$ & \\
\hline Gender & Male & 40 & $32(66.66)$ & $8(44.44)$ & 0.099 \\
\hline & Female & 26 & $16(33.33)$ & $10(55.55)$ & \\
\hline Site of Biopsy & Respiratory tree & 59 & $44(91.66)$ & $15(83.33)$ & 0.327 \\
\hline & Metastatic site & 7 & $4(8.33)$ & $3(16.66)$ & \\
\hline Smoking history & Smoker/Ex-Smoker & 21 & $20(41.66)$ & $1(5.55)$ & $0.005^{*}$ \\
\hline & Non-smoker & 45 & $28(58.33)$ & 17 (94.44) & \\
\hline Histological phenotype- & $\begin{array}{l}\text { Adenocarcinoma with squamous differentiation } \\
\text { (Primary and metastatic) }\end{array}$ & 2 & $1(2.08)$ & $1(5.55)$ & 0.463 \\
\hline $\begin{array}{l}\text { (Presence of squamous } \\
\text { differentiation) }\end{array}$ & $\begin{array}{l}\text { Adenocarcinoma with absence of squamous } \\
\text { differentiation (Primary and metastatic) }\end{array}$ & 64 & $47(97.91)$ & $17(94.44)$ & \\
\hline TTF-1 & Positive & 59 & $41(85.41)$ & $18(100)$ & 0.086 \\
\hline & Negative & 7 & $7(14.58)$ & $0(0)$ & \\
\hline Napsin & Positive & 61 & $43(89.58)$ & $18(100)$ & 0.154 \\
\hline & Negative & 5 & $5(10.41)$ & $0(0)$ & \\
\hline T stage $(\mathrm{n}=45)$ & $\mathrm{T} 1$ & 2 & $1(3.12)$ & $1(7.69)$ & 0.849 \\
\hline & $\mathrm{T} 2$ & 8 & $6(18.75)$ & $2(15.38)$ & \\
\hline & $\mathrm{T} 3$ & 13 & $10(31.25)$ & $3(23.07)$ & \\
\hline & $\mathrm{T} 4$ & 22 & $15(46.87)$ & $7(53.84)$ & \\
\hline $\mathrm{N}$ stage $(\mathrm{n}=45)$ & N0 & 18 & $12(37.5)$ & $6(46.15)$ & 0.225 \\
\hline & $\mathrm{N} 1$ & 10 & $9(28.12)$ & $1(7.69)$ & \\
\hline & $\mathrm{N} 2$ & 12 & $9(28.12)$ & $3(23.07)$ & \\
\hline & N3 & 5 & $2(6.25)$ & $3(23.07)$ & \\
\hline M stage $(n=45)$ & M0 & 23 & $17(53.12)$ & $6(46.15)$ & 0.671 \\
\hline & M1 & 22 & $15(46.87)$ & $7(53.84)$ & \\
\hline Clinical stage $(\mathrm{n}=45)$ & I & 2 & $2(6.25)$ & $0(0)$ & 0.801 \\
\hline & II & 6 & $4(12.5)$ & $2(15.38)$ & \\
\hline & III & 15 & $11(34.37)$ & $4(30.76)$ & \\
\hline & IV & 22 & $15(46.87)$ & $7(53.84)$ & \\
\hline Survival $(\mathrm{n}=50)$ & Upto 3 months & 11 & $10(27.02)$ & $1(7.69)$ & 0.369 \\
\hline & $>3$ months to 6 months & 10 & $6(16.21)$ & $4(30.76)$ & \\
\hline & $>6$ months to 12 months & 19 & $13(35.13)$ & $6(46.15)$ & \\
\hline & $>12$ months & 10 & $8(21.62)$ & $2(15.38)$ & \\
\hline
\end{tabular}




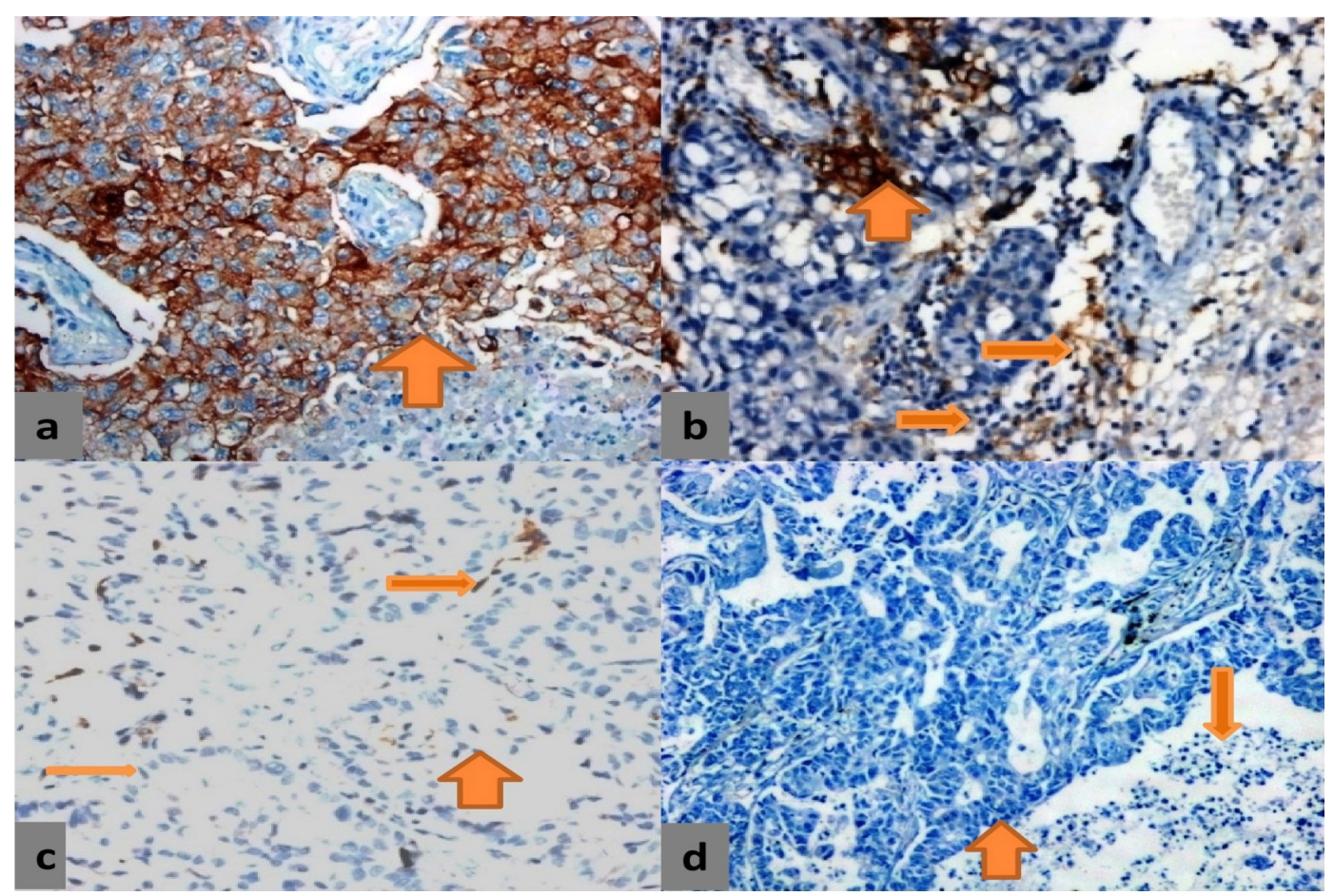

Figure 3 (a). Tumour and ICs are positive for PD-L1 (b): PD-L1 expression in tumour cells while ICs are negative (c): Tumour is negative while ICs are positive for PD-L1 (d): Tumour and ICs are negative for PD-L1 (DABx200)

\section{mutation}

The correlation of driver genes with the demographic characteristics are detailed in Table3. Presence of EGFR mutations had a significant association with smoking status $(\mathrm{p}=0.008)$, Thyroid transcription factor 1 (TTF1) $(\mathrm{p}=0.0005)$ and Napsin $(\mathrm{p}=0.002)$ expression. $A L K$ gene re-arrangement had significant correlation with age $(p=0.001)$, gender $(p=0.009)$ and smoking status $(p=0.043)$.

\section{Co-expression of driver mutations}

Driver mutations were identified in $60 \%(n=66 / 110)$
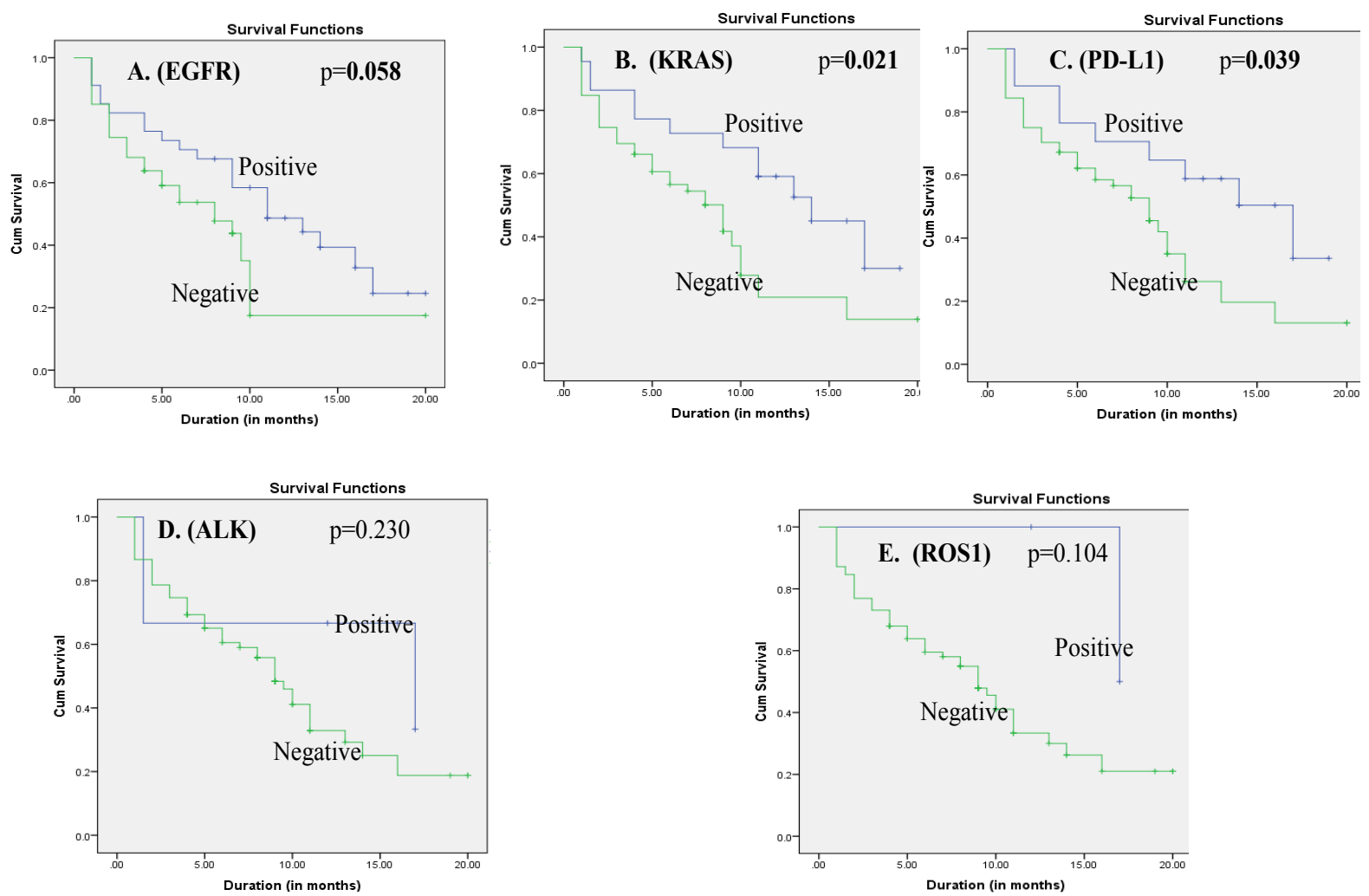

Figure 4. Kaplan-Meier Curve for Survival Time of A:EGFR, B:KRAS, C: PD-L1, D:ALK and E:ROS1 positive versus negative group 


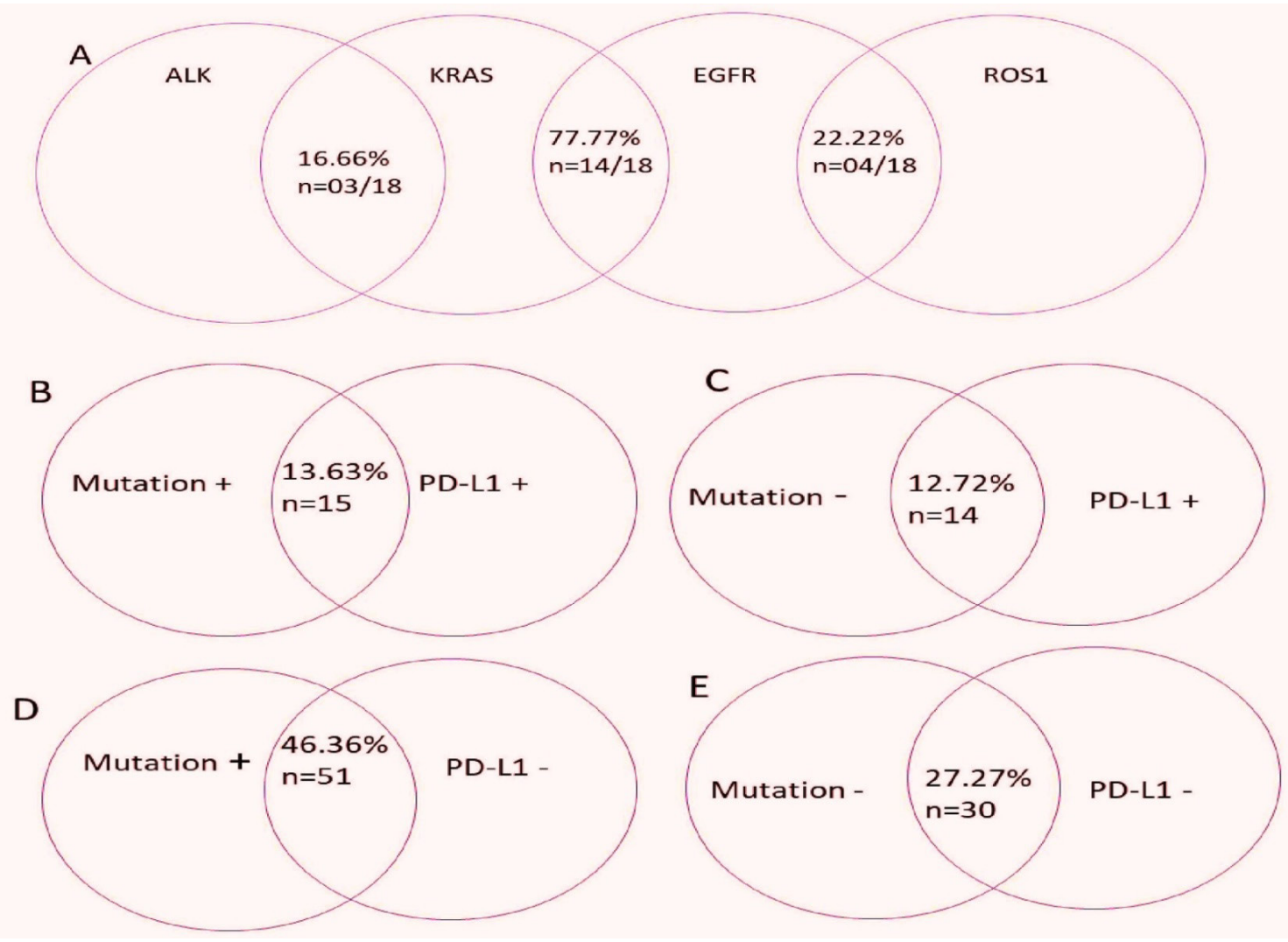

Figure 5. A) Co-expression of multiple driver mutations in NSCLC-Adenocarcinoma; B) Correlation of PD-L1 expression with presence of driver mutations; C) PD-L1 expression in the absence of driver mutations; D) Driver mutations in the absence of PD-L1 expression; E) Both driver mutations and PD-L1 are negative

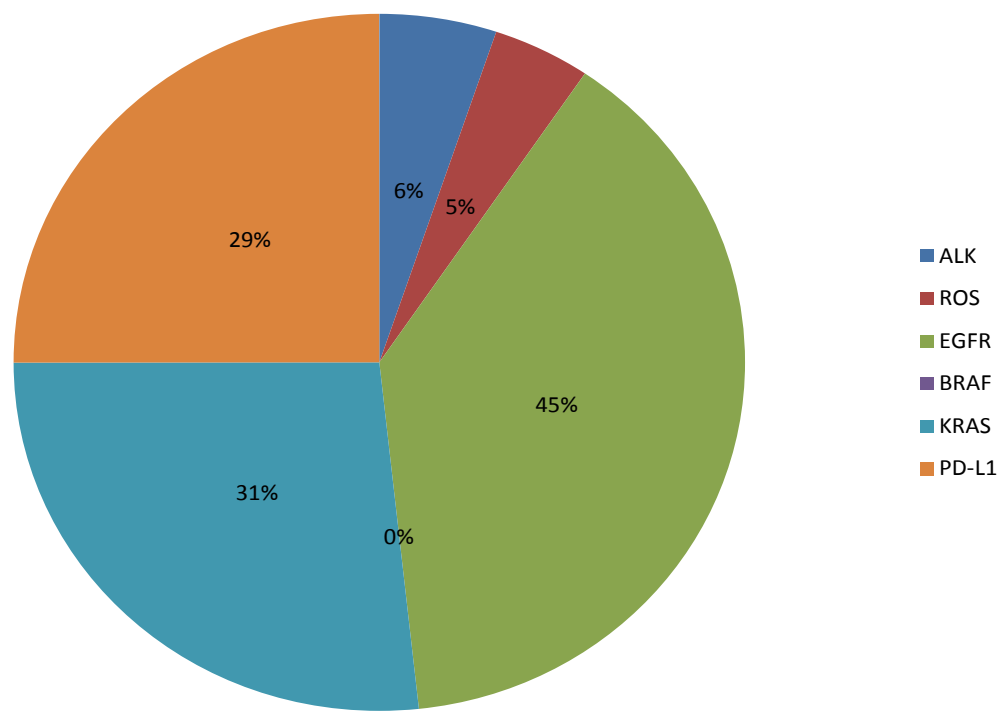

Figure 6. All Mutation's Frequency (\%) in Pie Chart

cases, Single driver mutation was present in $72.72 \%$ $(\mathrm{n}=48 / 66)$ cases, while multiple driver mutations were present in $27.27 \%(\mathrm{n}=18 / 66)$ cases (Table 5).

ALK and ROS-1 rearrangements were mutually exclusive. Co-expression of ALK with EGFR mutations was not found. Co-expression of ALK and KRAS was observed in $16.66 \%(\mathrm{n}=03 / 18)$ cases. Co-expression of ROS with EGFR mutations was observed in $22.22 \%$ $(n=04 / 18)$ cases. Co-expression of EGFR and KRAS was observed in $77.77 \%(n=14 / 18)$ cases. (Figure 5A) The single versus multiple driver mutations significantly correlated with smoking status $(\mathrm{p}=0.005)$.

\section{Correlation of $P D-L 1$ with driver mutations}

The presence of driver mutations in addition to PD-L1 expression was found in $13.63 \%(\mathrm{n}=15 / 110)$ cases (Figure 5B). In $12.72 \%(n=14 / 110)$ cases, PD-L1 expression was documented in the absence of driver mutations (Figure 
5C), while in $46.36 \%$ cases $(n=51 / 110)$, driver mutations were present in the absence of PD-L1 expression. (Figure 5D) and $27.27 \%(30 / 110)$ cases were negative for both driver mutations and PD-L1 (Figure 5E). However, there was no significant co-expression found between the PD-L1 expression and driver gene over-expression. PD-L1 positivity in TCs and ICs was also not significantly associated with the presence of driver (KRAS/EGFR/ ALK/ROS) mutations (Table 4).

\section{Survival Analysis}

Survival data of $81(73.63 \%)$ cases was determined. The mean follow-up time was 7.6 months (range 1 month to 20 months). Kaplan-Meier analysis was performed to investigate the prognostic significance of driver genes combined with PD-L1 expression. No correlation was observed between driver genes and PD-L1 immunopositivity $(\mathrm{p}=0.385)$ in the overall survival (OS). However, individual positive versus negative group PD-L1, KRAS, and EGFR were found statistically significant $(\mathrm{P}=0.039, \mathrm{P}=0.021$, and $\mathrm{p}=0.058)$ using $\log$ Rank test in overall survival (OS) (Figure 4). Further, survival analysis was performed in single and multiple driver gene mutations, however, this was not statistically significant $(\mathrm{p}=0.780)$.

\section{Discussion}

The clinical efficacy and safety of immune check point inhibitors targeting PD-1/PD-L1 have improved the prognosis for NSCLCs patients. Several recent studies have demonstrated that over-expression of PD-L1 is commonly associated with oncogene activation. However, these associations are questionable (Song et al., 2016; Lan et al., 2018).

PD-L1 immunopositivity varied from 13 to $70 \%$ in NSCLC phenotype in various studies (Kerr et al., 2015; Reck et al., 2016). In the current study, PD-L1 expression was identified in $(26.36 \%)$ cases of NSCLC-adenocarcinoma phenotype. The expression was not restricted to tumor cells only, but was also seen in the immune cells. In the present study, all cases with PDL1 expression were pure adenocarcinoma, whereas cases of adenocarcinoma with squamous differentiation did not show PDL1 expression. The finding contradicts the study conducted by Vallonthaiel et al., (2017), wherein the authors failed to document any specific histological subtype in the PD-L1 positive sub-group.

The associations between PD-L1 expression and gender remain controversial. A few studies published in the literature fail to demonstrate any significant relationship with gender (Vallonthaiel et al. 2017). In the current study, PD-L1 expression was more common in men than in women ( $65 \%$ versus $34 \%)(p=0.99)$ and non-smokers than in smokers ( $51 \%$ versus $48 \%)(p=0.23)$; however, the difference was not found to be statistically significant. Karatrasoglou et al., (2020) have documented that PD-L1 expression was more frequent in women and smokers.

When looking at the frequencies of driver genes ALK, ROS, EGFR, KRAS, and BRAFV600E in north
Indian patients, we have noted that patients with positive EGFR mutation showed the highest frequency. $A L K$ gene rearrangement was significantly associated with age $(p=0.001)$, gender $(p=0.009)$, and smoking status $(\mathrm{p}=0.043)$.

In the current study, the BRAFV600E protein over-expression was not documented in even a single case. This finding implies that BRAF mutations in NSCLC may involve alternative mutation sites and detailed molecular analysis is done in identifying true mutation frequency. In India, most cases of lung cancer are commonly diagnosed in advanced stages, where the mainstay of treatment is either targeted therapy or standard chemotherapy. In this study, the presence of multiple driver gene mutations has been assessed, and we found that $27.27 \%$ of cases harbored multiple driver gene mutations. Single versus multiple driver mutations were significantly correlated with smoking status $(\mathrm{p}=0.005)$. In this category, the most significant mutations occurred in EGFR than KRAS, and both were highly associated with each-other than the other driver groups. The presences of KRAS mutations show resistance against the traditional TKI therapy that is administered in cases that harbor EGFR mutations. Hence, the identification of this category is essential. PD-L1 is activated by oncogenic signaling pathways such as anaplastic lymphoma kinase/signal transducers and activators of transcription 3(ALK/STAT3) extracellularsignal-regulated kinases/mitogen-activated protein kinase (Erk/MAPK). The activation of the EGFR pathway in NSCLC may lead to PD-L1 upregulation (Ilie et al., 2016; Van et al., 2013; Akbay et al., 2013). EGFR mutated cases show lower response rates to PD-1/PD-L1 inhibitors than those with EGFR negative cases (Kerr et al., 2015; Rittmeyer et al., 2017). In the current study, the presence of multiple oncogenic driver mutations was co-related with the PDL1 expression in tumor cells (TCs) and immune cells (ICs). However, there was no significant correlation documented between PD-L1 immunopositivity and EGFR, KRAS, ALK, ROS, and BRAF driver mutations in the present study (Table 4). Co-expression of PD-L1 with driver mutations may suggest possibility of use of combination therapy.

The prognostic value of PD-L1 expression in NSCLC remains controversial, the association between PD-L1 expression and EGFR mutations has been assessed and analyzed in a few studies published in literature; however, the association is inconsistent. The current study showed higher PD-L1 expression in EGFR mutant cases followed by KRAS, ALK, and ROS rearrangements.PD-L1 detection in patients with lung cancer makes such patients suitable candidates for giving PD-L1 inhibitors, which impact therapeutic response. The association between driver mutations and PD-L1 expression shows that dual therapy might improve the quality of life as well as the overall survival rate of lung cancer patients

The current study calculates the overall survival (OS) rate of all the driver genes and PD-L1 cases. OS was statistically significant with EGFR $(p=0.058)$, KRAS ( $p=0.021)$, and PD-L1 ( $p=0.039)$, in the mutation-positive versus mutation-negative group. The Kaplan-Meier analysis revealed better survival rates with EGFR, 
KRAS, and PD-L1 biomarkers. This finding may suggest the use of combination therapy in treating the NSCLCadenocarcinoma subtype.

Our study has a few limitations; it is difficult to compare the results of the current study with earlier studies as different methodologies have been used to evaluate the presence of mutations and PD-L1 expression.

In conclusion, the current study is a novel attempt to document the co-expression of multiple driver mutations in the NSCLC-adenocarcinoma phenotype and to analyze the co-relation between PDL1 expression and the presence of driver mutations. We found that PD-L1 immunopositivity in NSCLC-adenocarcinoma was higher with EGFR mutation than those with $K R A S, A L K, R O S$, and $B R A F$ driver genes.

\section{Acknowledgements}

Author wish to acknowledge the Integral University, (Department of Biosciences) Lucknow, (UP), India for providing MCN NO (IU/R\&D/2021-MCN0001100), and Ph.D. registration to Mr. Rahul Kumar Pandey. Study was partially funded from Intramural research grant Dr. Ram Manohar Lohia Institute of Medical Sciences, Lucknow.

\section{Funding Statement}

The study was funded by Intramural project (IEC 12/17), Dr. Ram Manohar Lohia Institute of Medical Sciences (RMLIMS), Lucknow, India.

\section{References}

Aguiar Jr PN, De Mello RA, Hall P, Tadokoro H, Lima Lopes GD (2017). PD-L1 expression as a predictive biomarker in advanced non-small-cell lung cancer: updated survival data. Immunotherapy, 9, 499-506.

Akbay EA, Koyama S, Carretero J, et al (2013). Activation of the PD-1 pathway contributes to immune escape in EGFRdriven lung tumors. Cancer Discov, 3, 1355-63.

Al Azhar M, Aisyi M (2021). Profile of PD-L1 mRNA expression in childhood acute leukemia. Asian Pac J Cancer Biol, 6, $37-41$.

Biernacka A, Tsongalis PD, Peterson JD, et al (2016). The potential utility of re-mining results of somatic mutation testing: KRAS status in lung adenocarcinoma. Cancer Genet, 209, 195-8.

Chatziandreou I, Tsioli P, Sakellariou S, et al (2015). Comprehensive molecular analysis of NSCLC; clinicopathological associations. PLoS One, 10, 0133859.

Chen D, Zhang LQ, Huang JF, et al (2014). BRAF mutations in patients with non-small cell lung cancer: a systematic review and meta-analysis. PLoS One, 9, 101354.

Clayton SJ, Scott FM, Walker J, et al (2000). K-ras point mutation detection in lung cancer: comparison of two approaches to somatic mutation detection using ARMS allele-specific amplification. Clin Chem, 46, 1929-38.

Desai SS, Shah AS, Prabhash K, Jambhekar NA (2013). A year of anaplastic large cell kinase testing for lung carcinoma: Pathological and technical perspectives. Indian J Cancer, 50, 80 .

Edition S, Edge SB, Byrd DR (2017) AJCC cancer staging manual 8th edition. AJCC cancer staging manual.

Garon EB, Rizvi NA, Hui R, et al (2018). Pembrolizumab for the treatment of non-small-cell lung cancer. $N$ Engl J Med,
372, 28.

Gettinger S, Rizvi NA, Chow LQ, et al (2016). Nivolumab monotherapy for first-line treatment of advanced non-smallcell lung cancer. J Clin Oncol, 34, 2980.

Helmy DO, El-Sabah MT, Negm, MS, Armia MEO (2020). Diagnostic and pathologic value of programmed deathligand 1 expression in colon carcinoma. Asian Pac J Cancer Biol, 5, 159-66.

Ilie M, Hofman V, Dietel M, Soria JC, Hofman P (2016). Assessment of the PD-L1 status by immunohistochemistry: challenges and perspectives for therapeutic strategies in lung cancer patients. Virchows Arch, 468, 511-25.

Jain E, Sharma S, Aggarwal A, et al (2021). PD-L1 expression and its clinicopathologic and genomic correlation in the nonsmall cell lung carcinoma patients: An Indian perspective. Pathol Res Pract, 2021, 153497.

Karatrasoglou EA, Chatziandreou I, Sakellariou S, et al (2020). Association between PD-L1 expression and driver gene mutations in non-small cell lung cancer patients: correlation with clinical data. Virchows Arch, 477, 207-17.

Kerr KM, Tsao MS, Nicholson AG, et al (2015). Programmed death-ligand 1 immunohistochemistry in lung cancer: in what state is this art. $J$ Thorac Oncol, 10, 985-9.

Kim H, Yoo SB, Choe JY, et al (2011). Detection of ALK gene rearrangement in non-small cell lung cancer: a comparison of fluorescence in situ hybridization and chromogenic in situ hybridization with correlation of ALK protein expression. J Thorac Oncol, 6, 1359-66.

Kimberly DM, Rebecca LS, Chun CL, et al (2016). Cancer treatment and survivorship statistics. CA Cancer J Clin, 66, 271-89.

Koperek O, Kornauth C, Capper D, et al (2012). Immunohistochemical detection of the BRAF V600Emutated protein in papillary thyroid carcinoma. Am J Surg Pathol, 36, 844-50.

Lan B, Ma C, Zhang C, et al (2018). Association between PD-L1 expression and driver gene status in non-small-cell lung cancer: a meta-analysis. Oncotarget, 9, 7684.

Lantuejoul S, Sound-Tsao M, Cooper WA, et al (2020). PD-L1 testing for lung cancer in 2019: perspective from the IASLC Pathology Committee. J Thorac Oncol, 15, 499-519.

Mino-Kenudson M (2017). Immunohistochemistry for predictive biomarkers in non-small cell lung cancer. Transl. Lung Cancer Res, 6, 570.

Mohammadi M, Cao Y, Glimelius I, et al (2015). The impact of comorbid disease history on all-cause and cancer-specific mortality in myeloid leukemia and myeloma-a Swedish population-based study. BMC Cancer, 15, 1-2.

Pan ZK, Ye F, Wu X, An HX, Wu JX (2015). Clinicopathological and prognostic significance of programmed cell death ligand1 (PD-L1) expression in patients with non-small cell lung cancer: a meta-analysis. J Thorac Dis, 7, 462.

Piton N, Borrini F, Bolognese A, Lamy A, Sabourin JC (2015). KRAS and BRAF mutation detection: is immunohistochemistry a possible alternative to molecular biology in colorectal cancer?. Gastroenterol Res Pract, 2015.

Reck M, Rodríguez-Abreu D, Robinson AG, et al (2016). Pembrolizumab versus chemotherapy for PD-L1-positive non-small-cell lung cancer. N Engl J Med, 375, 1823-33.

Remon J, Hendriks LE, Cabrera C, Reguart N, Besse B (2018). Immunotherapy for oncogenic-driven advanced non-small cell lung cancers: Is the time ripe for a change?. Cancer Treat Rev, 71, 47-58.

Rimkunas VM, Crosby KE, Li D, et al (2012). Analysis of receptor tyrosine kinase ROS1-positive tumors in non-small cell lung cancer: identification of a FIG-ROS1 fusion. Clin Cancer Res, 18, 4449-57. 
Rittmeyer A, Barlesi F, Waterkamp D, et al (2017). Atezolizumab versus docetaxel in patients with previously treated non-small-cell lung cancer (OAK): a phase 3, open-label, multicentre randomised controlled trial. Lancet, 389, 255-65.

Song Z, Yu X, Cheng G, Zhang Y (2016). Programmed death-ligand 1 expression associated with molecular characteristics in surgically resected lung adenocarcinoma. $J$ Transl Med, 14, 1-7.

Sterlacci W, Fiegl M, Droeser RA, Tzankov A(2016). Expression of PD-L1 identifies a subgroup of more aggressive non-small cell carcinomas of the lung. Path Biol, 83, 267-75.

Sumimoto H, Takano A, Teramoto K, Daigo Y (2016). RAS-mitogen-activated protein kinase signal is required for enhanced PD-L1 expression in human lung cancers. PLoS One, 11, e 0166626.

Thelwell N, Millington S, Solinas A, Booth J, Brown T (2000). Mode of action and application of Scorpion primers to mutation detection. Nucleic Acids Res, 28, 3752-61.

Topalian SL, Hodi FS, Brahmer JR, et al (2012). Safety, activity, and immune correlates of anti PD 1 antibody in cancer. N Engl J Med, 366, 2443-254.

Towne P, McElhinny A, Nitta H (2012). VENTANA ALK Scoring Interpretation Guide for non small cell lung carcinoma (NSCLC). Germany: Ventana Medical Systems, Inc. and Roche Diagnostics International, Inc, 2013.

US Food and Drug Administration (2018). Therascreen ${ }^{\circledR}$ EGFR RGQ PCR kit instructions for use (handbook).

Vallonthaiel AG, Malik PS, Singh V, et al (2017). Clinicopathologic correlation of programmed death ligand-1 expression in non-small cell lung carcinomas: a report from India. Ann Diagn Pathol, 31, 56-61.

Van Rooij N, van Buuren MM, Philips D, et al (2013). Tumor exome analysis reveals neoantigen-specific T-cell reactivity in an ipilimumab-responsive melanoma. J Clin Oncol Am $J$ Clin Oncol, 31.

Watermann I, Schmitt B, Stellmacher F, et al (2015).Improved diagnostics targeting c-MET in non-small cell lung cancer: expression, amplification and activation. Diagn Pathol, 10, 1-2.

Whitcombe D, Theaker J, Guy SP, Brown T, Little S (1999). Detection of PCR products using self-probing amplicons and fluorescence. Nat Biotechnol, 17, 804-7.

This work is licensed under a Creative Commons AttributionNon Commercial 4.0 International License. 